condition after the necrotic process has begun and phthisis is a clinical entity. These points are of some importance and I trust that you will be good enough to give space to them. I am, Sirs, yours faithfully, Thomas W. DEWar.

Kincairn, Dunblane, N.B., May 22nd, 1905.

\section{FIFTH ANNUAL SOUTH AFRICAN CIVIL SURGEONS' DINNER.}

\section{To the Editors of THE LANCET.}

SIRS,--Through the medium of your journal we should like to call attention to the above dinner, which will take place on Tuesday, July 4th, at 8 o'clock, at the Imperial Restaurant, Regent-street. Mr. W. Watron Cheyne, C.B., has kindly consented to take the chair. Reply cards will be sent to those whose addresses are available and we hope that those who wish to attend will reply as soon as possible. The price of the dinner will be $10 s$. $6 \dot{d}$. (exclusive of wine)

We are, Sirs, yours faithfully,

Francts E. Fremantre, Honorary C. GORDON WATSON, Secretaries.

44, Welbeck-street, W., May 24th, 1905.

\section{UNPAID AS USUAL!}

\section{To the Editors of THE LANCET.}

Sins, - I received a few days ago a letter from the senior medical officer of the volunteer infantry brigade to which $I$ belong. I inclose a copy of it.

A number of volunteer medical officers will be required for duty in the station hospitals of the regular army during the training season (May to August) Those officers would not, of course [the italics are mine], receive pay nor would any expense to the public be admissible, hence their attendance must be entirely voluntary. Should you be willing, \&c.

Comment is, perhaps, superfluous, but one cannot help observing what an encouragement such a proposal must be to the volunteers to perfect themselves as a reserve to the regular forces. Do our colleagues in the Royal Army Medical Corps serve during the training season without pay and with no expense to the public?

That such an offer can be seriously made to qualified medical men with, presumably, some idea of a more or les: favourable response points to the urgent necessity of some strong professional combination, while the fact that the War Otfice considers it probable or even possible that commissioned officers of the auxiliary forces may be willing to perform public duties without any expense to the public, but at a considerable loss to themselves, and alongside officers of the regulars and militia who are drawing full rates of pay and allowances for the performance of the sime duties, only indicates the utter futility of any hope of any improved position for the volunteer or any practical recognition of him as a genuine factor in any scbeme of national defence. It is to be devout.ly hoped that volunteer medical officers with any respect for their profession or for the force to which they belong will bave nothing to do with this proposal.

I am, Sirs, yours faithfully,

May 20th, 1905.

A. M. R.

\section{MANCHESTER.}

\section{(FROM OUR OWN CORRESPONDENT.)}

\section{Physique of Salford Children.}

Mr. C. H. Tattersall, the medical officer of health of Salford, and the assistant medical officer, Dr. J. J. Butterworth, give interesting reports on the medical work done by them in 1904 for the Salford education committee. There are 4000 children in Salford attending school who are under five years of age and $\mathrm{Mr}$. Tattersall agrees with many others who have studied the question that the attendance of these children should be discouraged, believing that "the sixth year is early enough for a child to attend school." There is considerable difference in the social condition of the neighbourhoods in which the six schools selected for observation are situated and the schools differ considerably also. 1. Boys chiefly from the clars of clerks, warehousemen, and shop keepers. The boys are clean, well nourished, and sufficiently clothed. The school is surrounded by a large open space and has a very large playyround. 2. Boys chiefly the sons of unskilled labourers. Clothing is deficient both in quality and quantity, not one boy wearing an under-vest. Vermin are very prevalent. 3. Boys from the skilled artisan class and latterly a good many children of dock labourers. The neighbourhood has of late become thickly populated. 4. Scholars chiefly from the skilled artisan and clerk class. They are well dressed and nourished, each boy wearing two garments, an under-vest and shirt. The school is close to a large park. 5. Here the boys are chiefly the sons of mill-workers. They are well but roughly clothed and well nourished. There is a large playing field attached to the school. 6. This school is situated in what is still regarded, in spite of some improvement in late years, as the worst district in Salford. It is, as one would expect, densely populated. In these six schools, three of a better and three of a poorer class, records were taken of the height, weight, and chest girth of all the boys between the ages of seven years and nine months and eight years and three months, between nine years and nine months and ten years and three months, and between 12 years and nine months and 13 years and three months. This gave three age periods approximately of eight, ten, and 13 years. As would be expected, in the three higher class schools-i.e., in those where the social conditions and the surroundings are comparatively more favourable for healthy existence-the physique is better than in the three poor schools. At the age of eight years all are fairly equal, but at 13 years there are marked differences. As showing that something more than mere rocial condition affects the result there is a seeming exception in the case of No. 5 school which stands at the top of the list as to physique, altbough the boys are roughly clothed children of mill-workers. They are, however, well fed and "attached to the school is a large playing-field" in an open situation. This appears the chief factor likely to account for the better growth and development of the No. 5 boys, who at 13 vears of age are two and a third inches taller and 13 pounds heavier than those of No. 3 school, the latter being chiefly the sons of skilled artisans. Over those of No. 6 -cbool they have the advantage of being nearly four inches taller and about 14 pounds heavier. As the e boys will most of them earn their living by bodily work the advantage at the start should always keep them in front of those less favoured. In accounting for the marked superiority of the boys in No. 5 school it may be mentioned that the district is one where the social and moral tone is somewhat above the average. "More than 90 per cent. of the children attend Sunday school," the people keep early hours, and " the children are abed betimes." As Mr. Tattersall says, impr per feeding and under-feeding have marked consequences; where the people are poor and the children are badly fed the physique shows the natural result. On the other hand, he does not blame the mothers for want of care of their young children and he finds that more than 90 per cent. of these have been breastfed. These working class mothers set a good example to those in more comfortable positions. There has been of late considerable improvement in this respect, for three or four years ago only 70 per cent. of these Salford mothers fed their children from the breast. He advocates "breastfeeding and teetotalism on the part of the mothers." Some of the schools are well provided with facilities for outdoor play but others are not. No. 6 school, where the children are "dirty, badly clothed, and ill-nourished" and where "a large proportion showed distiuct signs of rickets" is situated in Greengate, the worst district in Salford and has none of these advantages close at hand, and the cbildren would rather play in a dirty crowded slum near home than in a park at a distance. Now that attention is so much directed to this question it is to be hoped that sensible measures will be taken to improve as much as possible the evil inflaences of our manufacturing towns on the physique of their inhabitants. It is a matter of the gravest import to the future of our race and it will be a sorry result of our civilisation if " men decay." Although there are some encouraging fact- it is not cheering, to quote the words of a careful observer, that "the average of child physique is lower in Salford than in any town in Great Britain of which record has been taken, with the possible exception of Rochdale." Our sanitarians have plenty of work before them in the improvement of hygienic conditions, while our moral sanitarians have a harder and, perhaps, more important task still in belping the people to understand and to live a bigher life physically than the groveller in the slums ever dreams of. 